\title{
Effects of Interleukin-6 on the Expression of Tight Junction Proteins in Isolated Cerebral Microvessels from Yearling and Adult Sheep
}

\author{
Susan S. Cohen May Min Erin E. Cummings Xiaodi Chen \\ Grazyna B. Sadowska Surendra Sharma Barbara S. Stonestreet \\ Department of Pediatrics, The Alpert Medical School of Brown University, Women and Infants Hospital of \\ Rhode Island, Providence, R.I., USA
}

\section{Key Words}

Blood-brain barrier · Cerebral microvessels · Interleukin-6 .

Tight junction proteins · Sheep

\begin{abstract}
Objectives: The blood-brain barrier is a selective diffusion barrier between brain parenchyma and the intravascular compartment. Tight junctions are integral components of the blood-brain barrier. Pro-inflammatory cytokines are important in the pathogenesis of brain injury and could modify the protein constituents of tight junctions. We hypothesized that interleukin-6 (IL-6) downregulates key protein constituents of endothelial tight junctions (e.g. occludin and claudin-5). Methods: We examined the effects of IL-6 on tight junction protein expression using an in vitro blood-brain barrier model. We isolated microvessels from yearling and adult ovine cerebral cortex and placed them into culture with IL-6 concentrations of 0 (control, phosphate-buffered saline), 1, 10, and $100 \mathrm{ng} / \mathrm{ml}$ for $24 \mathrm{~h}$. Cerebral microvessels were harvested, Western immunoblot performed for occludin and claudin-5, densitometry performed, and results expressed as a ratio to control values. Results: Western immunoblot analysis showed that treatment with $100 \mathrm{ng} / \mathrm{ml}$ of IL6 , but not the lower concentrations, reduced $(p<0.05)$
\end{abstract}

\section{KARGER}

E-Mail karger@karger.com

www.karger.com/nim occludin expression in microvessels from yearling and adult sheep and claudin-5 in microvessels from adult sheep. However, treatment with $10 \mathrm{ng} / \mathrm{ml}$ of IL-6 increased claudin- 5 in microvessels from yearling sheep. The percent of lactate dehydrogenase released from the microvessels into the surrounding media was not increased by IL- 6 treatment, suggesting that the reductions in tight junction proteins did not result from cell death. Treatment of adult cerebral cortical microvessels with IL- 6 preincubated with anti-IL- 6 monoclonal antibodies partially attenuated the reduction in claudin-5. Conclusion: We conclude that IL-6 modulates tight junction protein expression in cerebral cortical microvessels from yearling and adult sheep.

Copyright $\odot 2013$ S. Karger AG, Basel

\section{Introduction}

The blood-brain barrier is a selective diffusion barrier that maintains central nervous system (CNS) homeostasis and limits the entry of substances that could alter neuronal function. This structure is composed of specialized endothelial cells that line cerebral microvessels and possess a low nonspecific permeability to polar substances [1]. The cerebral microvascular endothelium, together 
with associated astrocytes, pericytes, neurons, and the components of the extracellular matrix, constitutes the neurovascular unit $[1,2]$. The neurovascular unit is essential for the health and function of the CNS in adult subjects and during development [2].

Although all components of the neurovascular unit, including the cellular constituents and basement membrane, contribute to the integrity of the blood-brain barrier, tight junctions of the endothelial cells represent the primary restrictive barrier $[1,2]$. Tight junction complexes form a continuous circumferential belt that separates the apical and basolateral plasma membrane domains, thus forming a fence within the plasma membrane $[3,4]$. Occludin and claudin are key transmembrane proteins that form the physical barrier characteristic of tight junctions [5] and serve to restrict paracellular diffusion between endothelial cells [2]. It is becoming increasingly apparent that blood-brain barrier dysfunction at the level of the tight junction is a critical event in the development and progression of several disorders that affect the CNS [2].

The role of pro-inflammatory cytokines in brain injury has become evident in many neurological disorders in the adult, such as Alzheimer's disease, Parkinson's disease, prion diseases, and AIDS-related dementia [6]. Additionally, Leviton et al. [7], in a seminal study, showed that infants with postmortem bacteremia were more likely to exhibit brain damage than were infants whose blood cultures were sterile, and postulated that noninfectious circulating inflammatory products could result in brain damage [7]. Furthermore, intrauterine infection or maternal chorioamnionitis has also been associated with umbilical cord endothelial activation, with upregulation of cell adhesion molecules, and systemic elevations in IL-6 levels in infants [8-10]. Importantly, elevated IL-6 levels have consistently been associated with brain damage in infants $[9,11-13]$.

The blood-brain barrier is also an interactive interface that regulates the ways in which the CNS and the immune system communicate with one another [6]. Previous in vitro work has shown that pro-inflammatory cytokines can increase the permeability of some endothelial barriers [14-16]. Specifically, IL-6 has been shown to increase the permeability of bovine-derived aortic endothelial monolayers [14] and confluent human umbilical vein endothelial cell monolayers in vitro [17].

Successful isolation of the brain microvasculature and development of in vitro models of the blood-brain barrier has facilitated understanding of the molecular characteristics of the blood-brain barrier. In fact, cerebral microvessels have been used as a reliable in vitro model of the blood-brain barrier and have been isolated from brain of a variety of animals including rat, bovine, and sheep [18-22]. Microvessel capillary fragments consist of endothelial cells ensheathed by basement membranes which contain pericytes to which astrocytic foot processes and nerve ending remnants can adhere, thus retaining many of the properties of the neurovascular unit [23]. In this model, three-dimensional aspects of the blood-brain barrier remain intact and several elements of the neurovascular unit may be maintained, unlike endothelial monolayers.

Sheep have been used extensively to investigate many aspects of CNS homeostasis [24,25]. The development of the ovine brain is similar to that of the human infant with respect to completion of neurogenesis, cerebral sulcation, and detection of the cortical component of auditory and somatosensory evoked potentials [26-28]. In addition, we have previously characterized the development of blood-brain barrier function in sheep [25]. Moreover, the brains of higher-level mammals, including humans and sheep, have extensive gyrations at birth in order to maximize cortical surface area, whereas the rodent brain is almost completely agyric. Although microvessels have been isolated from a number of species, only a few studies have previously reported the use of microvessels isolated from ovine brain $[19,20]$. As in the bovine model, the ovine brain provides an ample amount of cerebral cortical tissue for isolation of microvessels in sufficient quantities for complex in vitro studies.

In the current study, we isolated microvessels from yearling and adult sheep to complement our previous in vivo work $[25,29]$. We examined the effects of the proinflammatory cytokine interleukin-6 (IL-6) on tight junction protein expression using in vitro microvessels, and tested the hypothesis that that IL-6 downregulates key protein constituents of endothelial tight junctions.

\section{Methods}

Cerebral Cortical Microvessel Isolation

For each experimental procedure described below, the brains from 5 adult and 5 yearling sheep were obtained from a local supplier and transported to the laboratory in a cold transport solution [480 ml phosphate-buffered saline (PBS); Bio-Rad Laboratories, Hercules, Calif., USA; $10 \mathrm{ml}$ penicillin-streptomycin liquid; GIBCO, Invitrogen, Carlsbad, Calif., USA; $10 \mathrm{ml}$ Fungisone; GIBCO, Invitrogen]. Based upon documentation by the farmers and dating by the supplier, the adult sheep were at least 3 years of age and the yearling sheep less than 1 year of age. Yearling sheep were used because they were commercially readily available and reflected a developmentally younger population than the adult sheep. 
Microvessels were isolated from ovine brains using methods adapted with minor modifications from Sanchez del Pino et al. [30]. Using sterile procedures, the meninges were carefully removed from the cerebral cortical grey matter. The cerebral cortical tissue was homogenized with cold PBS and $26 \%$ dextran solution (Sigma-Aldrich, St. Louis, Mo., USA) in equal volumes with a blender (Hamilton Beach, Southern Pines, N.C., USA) at minimum speeds for nine 5 -second pulses separated by 10 -second intervals. The resultant mixture was centrifuged at $6,000 \mathrm{~g}$ for $10 \mathrm{~min}$ at $4^{\circ} \mathrm{C}$ and the pellet was washed with cold HEPES buffer ( $5 \mathrm{~g}$ HEPES and $1 \mathrm{~g}$ dextrose, both from Sigma-Aldrich, and 1 liter PBS). The pellet was then resuspended with cold PBS and homogenized using a motorized tissue grinder at approximately 1,500 rpm for 10 strokes (Wheaton Industries, Millville, N.J., USA). An equal amount of cold $26 \%$ dextran solution was added to the homogenate, and this mixture was centrifuged again at $6,000 \mathrm{~g}$ for $10 \mathrm{~min}$ at $4^{\circ} \mathrm{C}$. The pellet was washed with cold HEPES buffer, resuspended in cold PBS, and centrifuged at $3,000 \mathrm{~g}$ for $10 \mathrm{~min}$ at $4^{\circ} \mathrm{C}$. The resulting pellet was again washed with cold HEPES buffer, resuspended in cold PBS, and homogenized using a motorized tissue grinder at $1,500 \mathrm{rpm}$ for 10 strokes. The final homogenate was filtered over a $200-\mu \mathrm{m}$ nylon mesh using approximately 2 liters of cold PBS. The resultant solution was again filtered over a $120-\mu \mathrm{m}$ nylon mesh. The microvessel solution was filtered over a $20-\mu \mathrm{m}$ nylon mesh using an additional 1 liter of cold PBS. The microvessels remaining on top of the $20-\mu$ m nylon mesh were collected and resuspended in cold PBS. This solution was inspected microscopically (fig. 1) for purity prior to centrifugation for $15 \mathrm{~min}$ at $4,500 \mathrm{~g}$ at $4^{\circ} \mathrm{C}$. The resultant pellet was resuspended using $16 \mathrm{ml}$ of complete media warmed to $37^{\circ} \mathrm{C}(186 \mathrm{ml}$ Dulbecco's Modified Eagle Medium Nutrient Mixture F-12; Ham, GIBCO, Invitrogen; $10 \mathrm{ml}$ Charcoal/Dextran Treated FBS; Hyclone, Logan, Utah, USA; $2 \mathrm{ml}$ penicillin-streptomycin liquid, and $2 \mathrm{ml}$ Fungizone). Two milliliters of resuspended microvessels were pipetted into sterile culture flasks in order to coat the bottom of the flask ( $75 \mathrm{~cm}^{2}$ cell culture flask; Corning Inc., Corning, N.Y., USA). Then, $17 \mathrm{ml}$ of complete media was pipetted into each culture flask and the microvessels remained at $37^{\circ} \mathrm{C}$ for $16 \mathrm{~h}$. The 16 -hour rest period allowed for recovery of the microvessels after the extraction procedure. This rest period was based upon previous work suggesting that the energy state could be compromised, inducing a metabolic shock-like phenomena in bovine microvessels after similar isolation procedures [31,32]. On the other hand, incubation of the metabolically stressed microvessels in enriched tissue culture media improved the metabolic status of the microvessels [32]. Therefore, the microvessels were allowed to recover from the isolation procedures before exposure to the IL- 6 protein.

\section{Incubation of Microvessels with IL-6 Protein}

Each flask was inspected visually to determine that the microvessels had adhered to the bottom of the flask and for microvessel density and purity before incubation with the experimental treatments. IL-6 (Cell Sciences, Canton, Mass., USA) was reconstituted with PBS into concentrations of 20, 200, and 2,000 ng/ml, such that when the solutions were added to each flask the final concentrations of IL- 6 were 1,10 , or $100 \mathrm{ng} / \mathrm{ml}$, respectively. Clinically relevant IL-6 concentrations were selected for the experimental conditions based upon reports suggesting similar serum concentrations in neonates that subsequently developed brain

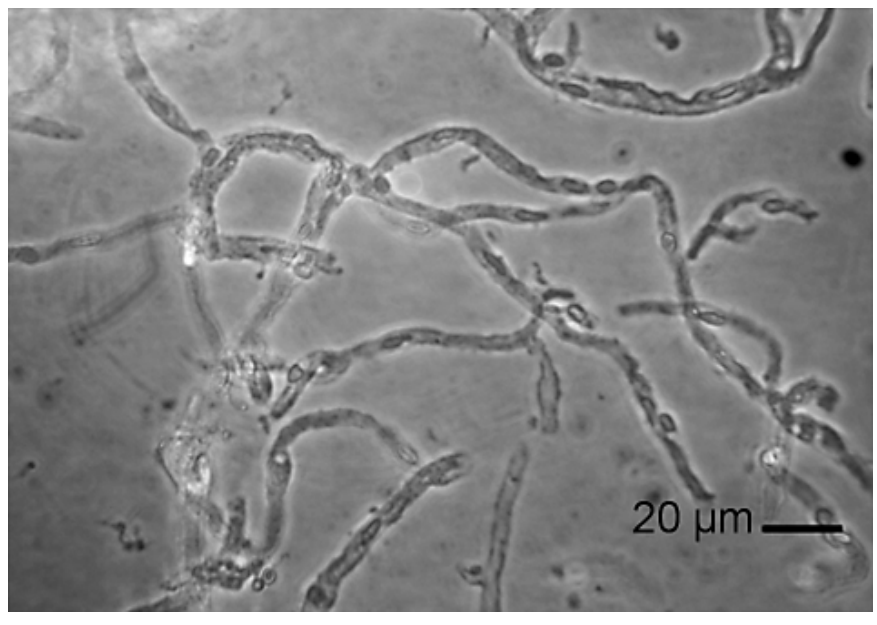

Fig. 1. Magnification $(\times 40)$ of microvessels from adult ovine brain at the end of the isolation procedure.

damage [13]. PBS was added to the media to replace the IL-6 protein and used to represent the nontreated control condition in each experiment. Each flask containing the microvessels and PBS or one of the three experimental concentrations of IL- 6 was incubated at $37^{\circ} \mathrm{C}$ for $24 \mathrm{~h}$ in culture media.

\section{Microvessel Co-Stimulation Assay with IL-6 Protein and Anti-IL-6 Antibody}

Microvessels from adult sheep brains were used for this portion of the study. Each flask of microvessels was examined as described above. IL- 6 was reconstituted using PBS and divided into aliquots with concentrations of $2,000 \mathrm{ng} / \mathrm{ml}$, such that when the solutions were added to each flask the final concentration of IL-6 was $100 \mathrm{ng} / \mathrm{ml}$. In order to have adequate monoclonal antibodies (mAbs) to bind to the IL-6 protein, the concentrations of mAbs that we used were several orders of magnitude higher than the protein concentration. Anti-IL6 human antibody (catalog No. 855.050.005; Cell Sciences) was reconstituted using PBS and divided into aliquots with concentrations of $20 \mu \mathrm{g} / \mathrm{ml}$. This concentration was designed to be 10 -fold greater than the concentration of the IL-6 protein, which was $100 \mathrm{ng} / \mathrm{ml}$. This $\mathrm{mAb}$ is an IgG1 neutralizing antibody made by the company (Cell Sciences) that produced the human IL- 6 protein used in the experiments above. It specifically recognizes the recombinant human IL-6 and exerts its biological activity by inhibiting IL-6 binding to its receptor.

The ovine microvessel co-stimulation assay was performed as follows: IL-6 protein was preincubated with anti-IL- 6 antibody for $1 \mathrm{~h}$ at $4^{\circ} \mathrm{C}$. Subsequently, each of the 4 flasks of microvessels was incubated for $24 \mathrm{~h}$ at $37^{\circ} \mathrm{C}$ in culture media with either PBS, IL-6 with a final concentration of $100 \mathrm{ng} / \mathrm{ml}$, anti-human IL- 6 antibody with a final concentration of $1 \mu \mathrm{g} / \mathrm{ml}$, or the IL- 6 protein $(100 \mathrm{ng} / \mathrm{ml})$ that had been preincubated with anti-IL-6 antibody $(1 \mu \mathrm{g} / \mathrm{ml})$. To test the specificity of the anti-IL- 6 antibody, we also pre-incubated IL- 6 protein with a nonspecific antibody at a concentration 10-fold greater than the concentration of IL-6 (Mouse IgG1 control; Cell Sciences). The additional control experiments were performed with the nonspecific mouse anti-IgG1 antibodies 
to establish that the nonspecific antibodies did not have the same effect as the specific anti-cytokine antibodies. At the end of the experiments, the microvessels were harvested from the culture flasks.

\section{Lactate Dehydrogenase Assay}

Lactate dehydrogenase (LDH) is an enzyme that is used as a marker for cell disruption and/or death [33]. The activity of extracellular, i.e. released, LDH was measured in the capillary-free supernatant and compared to the total LDH activity achieved after lysis of the capillaries with Triton X-100 (1\% in cell culture medium, $30 \mathrm{~min}$ at $37^{\circ} \mathrm{C}$ ). Samples containing $50 \mu \mathrm{g}$ of protein were tested using a standard LDH assay protocol (OPS Diagnostics, LLC; Lebanon, N.J., USA). A 96-well microplate reader (Multiskan RC; Thermo Scientific, Portsmouth, N.H., USA) was used for colorimetric detection at an absorbance of $492 \mathrm{~nm}$. The released LDH activity was expressed as a percentage of the total $\mathrm{LDH}$ activity [34].

\section{Western Immunoblotting}

The expression of occludin and claudin-5 was measured by Western immunoblot. Cerebral cortical microvessel samples were homogenized in Triton/deoxycholate/SDS (100 mM NaCl, 1\% Triton $\mathrm{X}, 0.5$ sodium deoxycholate, $0.2 \%$ SDS, $2 \mathrm{~mm}$ EDTA, $1 \mathrm{~mm}$ benzamidine) buffer containing $1 \%$ protease inhibitor cocktail (Sigma, St. Louis, Mo., USA) on ice for $10 \mathrm{~min}$, and centrifuged at $16,000 \mathrm{~g}$ for $30 \mathrm{~min}$ to extract the membrane-associated proteins. The supernatants were collected and the protein content was determined using a bicinchoninic acid protein assay (BCA, Pierce, Rockford, Ill., USA) with bovine serum albumin as a standard.

Different amounts of yearling and adult sheep protein from the microvessels were loaded due to preliminary findings of differences in intensity of the chemiluminescent signal (i.e. higher in yearling than adult sheep) when microvessels from the two age groups were loaded in similar concentrations. Hence, $4 \mu \mathrm{g}$ of protein for the microvessels from the yearling sheep and $12 \mu \mathrm{g}$ of protein for the microvessels from the adult sheep proved optimal and were loaded onto NuPAGE Novex 4-12\% Bis-Tris Midi Gel (Invitrogen, Carlsbad, Calif., USA) and immunoblotted to PVDF membranes $(0.2 \mu \mathrm{m}$; Bio-Rad Laboratories) using a semi-dry technique. The membranes were blocked with 5\% nonfat milk in Tris-buffered saline with Tween (TBST) buffer for $1 \mathrm{~h}$ at room temperature, washed in TBST 3 times for $10 \mathrm{~min}$ per wash, and incubated overnight at $4{ }^{\circ} \mathrm{C}$ with the appropriate primary antibody solution. The proteins were probed with the anti-claudin- 5 antibody (mouse polyclonal; Invitrogen) and anti-occludin antibody (mouse polyclonal; Invitrogen) at dilutions of 1:10,000 and 1:2,000, respectively. In addition, vinculin (mouse monoclonal; Thermo Scientific) at a dilution of 1:10,000 and glyceraldehyde-3-phosphate dehydrogenase (GAPDH, mouse monoclonal; Imgenex, San Diego, Calif., USA) at a dilution of 1:5,000 expressions were used as loading controls to ensure that equal amounts of protein were applied to each lane for the incubation of the microvessels with IL- 6 protein, and for the microvessel co-stimulation assay with IL- 6 protein and anti-IL-6 antibody, respectively. We used vinculin as the loading control in the studies of incubation of the microvessels with IL- 6 protein (fig. 2, 3). However, we were not able to achieve consistent results for vinculin due to technical difficulties in the costimulation assay studies (fig. 4). Consequently, GAPDH was used as a loading control for the costimulation assay studies (fig. 4).

IL-6 and Tight Junction Proteins

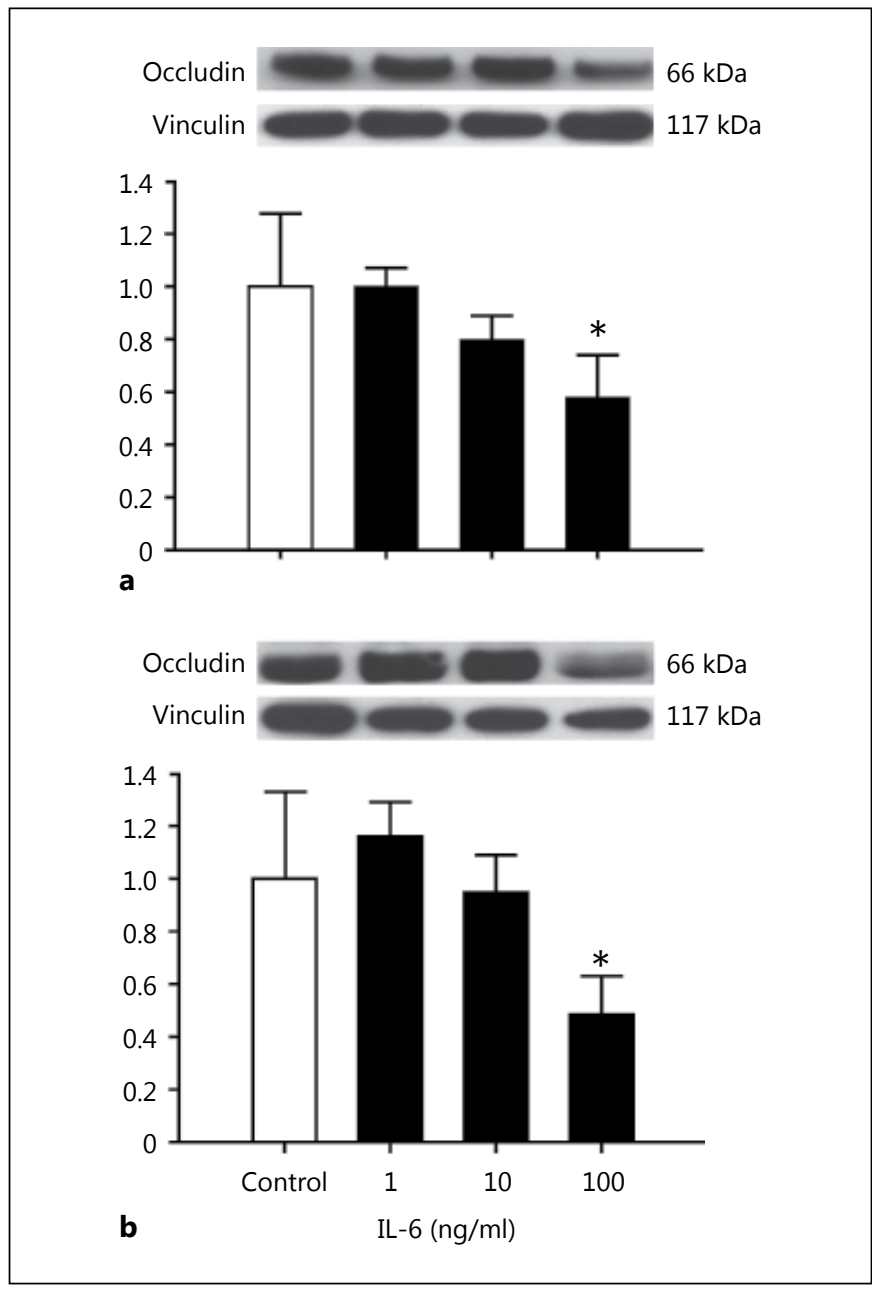

Fig. 2. a Occludin expression in isolated cerebral microvessels after incubation with IL- 6 for $24 \mathrm{~h}$. Results obtained from microvessels from the yearling lambs. Representative Western immunoblots for occludin and vinculin. Bar graphs represent results shown as ratios to PBS control treated microvessels. The open bar represents control treated microvessels set to a value of $1, n=5$; closed bars are IL- 6 treated, $\mathrm{n}=5$. Values are means \pm SEM. ${ }^{*} \mathrm{p}<0.05$ vs. control. b Occludin expression in isolated cerebral microvessels after incubation with IL-6 for $24 \mathrm{~h}$. Results obtained from microvessels from the adult sheep. Representative Western immunoblots for occludin and vinculin. Bar graphs, numbers, and statistics are as for $\mathbf{a}$.

The immunoblots were washed 3 times in TBST for 10 min per wash and incubated for $1 \mathrm{~h}$ at room temperature with goat antimouse secondary antibody (Zymed, San Francisco, Calif., USA) at a dilution of 1:10,000 for claudin-5, occludin, vinculin, and GAPDH. After incubation with secondary antibodies, immunoblots were again washed 4 times in TBST for 10 min per wash. Binding of the secondary antibody was detected with enhanced chemiluminescence (ECL-plus) Western blotting detection reagents (Amersham Pharmacia Biotech Inc., Piscataway, N.J., USA) and exposed to Hy- 


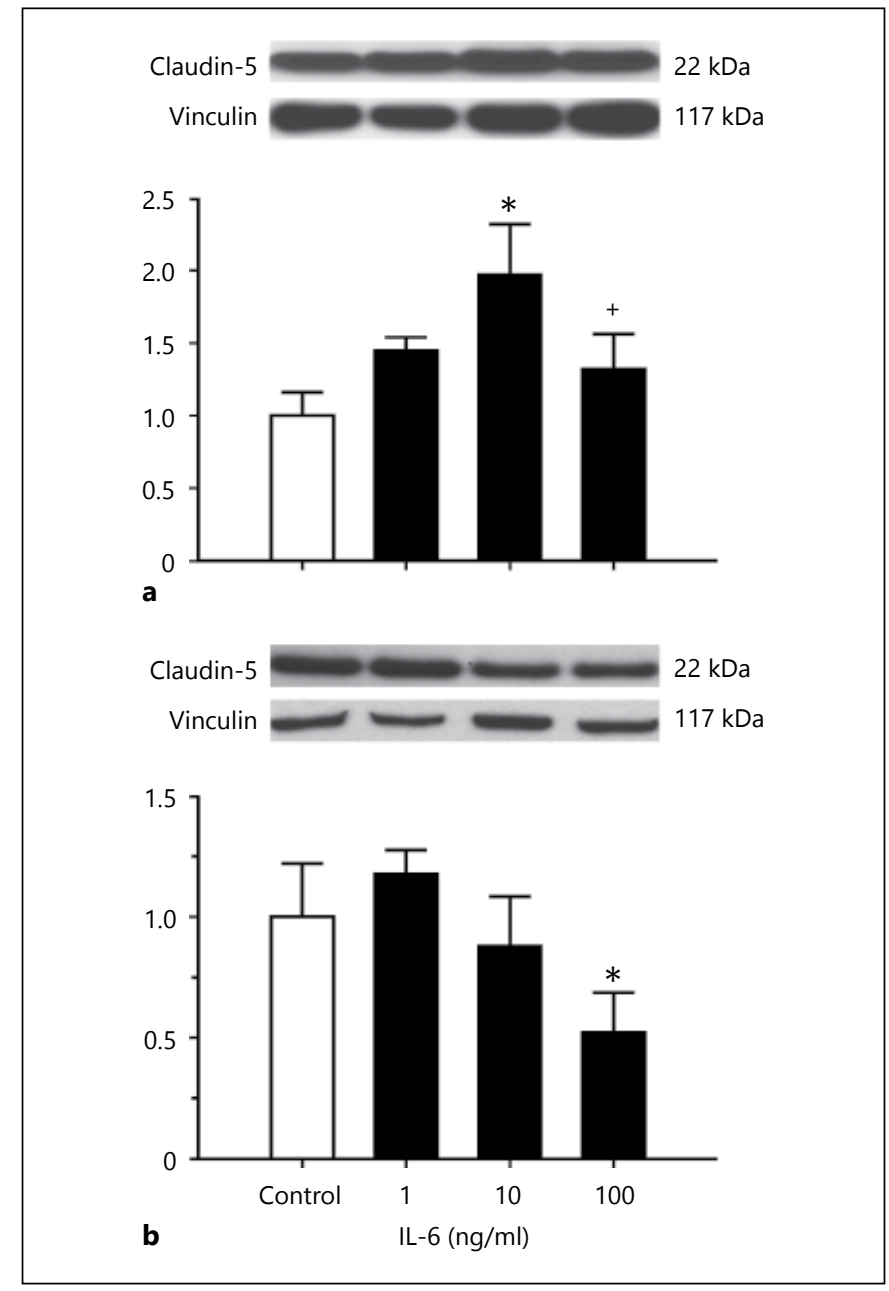

Fig. 3. a Claudin- 5 expression in isolated cerebral microvessels after incubation with IL- 6 for $24 \mathrm{~h}$. Results obtained from microvessels from the yearling sheep. Representative Western immunoblots for claudin-5 and vinculin. Results are shown as ratios to PBS control treated microvessels. Bar legends and numbers are as for figure 2 . Values are means \pm SEM. ${ }^{*} \mathrm{p}<0.05$ vs. control. ${ }^{+} \mathrm{p}<0.05$ vs. $10 \mathrm{ng} / \mathrm{ml}$. b Claudin -5 expression in isolated cerebral microvessels after incubation with IL-6 for $24 \mathrm{~h}$. Results obtained from microvessels from the adult sheep. Representative Western immunoblots for claudin-5 and vinculin. Results are shown as ratios to PBS control treated microvessels. Bar legends and numbers are as for figure 2 . Values are means \pm SEM. ${ }^{*} \mathrm{p}<0.05$ vs. control.

perfilm ECL (Phenix, Candler, N.C., USA). Uniformity in interlane loading was established by Coomassie blue (Sigma) staining of the polyacrylamide gels, and uniformity of transfer to the PVDF membranes was confirmed by Ponceau S (Sigma).

Densitometric Analysis

Band intensities were analyzed with a Gel-Pro Analyzer (Media Cybernetics, Silver Spring, Md., USA). The final values represented an average of the densitometric values obtained from 2-3 dif- ferent immunoblots. The densitometric values were presented as a ratio to the densitometric values of the microvessels that were exposed to the control PBS condition.

\section{Statistical Analysis}

One-way analysis of variance (ANOVA) was used to compare values among the different treatment conditions (Statistica Software, Stat Soft Inc., Tulsa, Okla., USA). Treatment conditions were compared separately for cerebral cortical microvessels from the yearling and adult sheep. If a significant difference was found by ANOVA, the Fisher least significant difference test was used to detect specific differences among the treatment conditions. Values are expressed as means \pm SEM. Differences were considered statistically significant if $\mathrm{p}<0.05$.

\section{Results}

Figure 1 shows the ovine microvessels after isolation and purification.

\section{Effects of Incubation with IL-6 on the Expression of \\ Tight Junction Proteins}

Compared to the control PBS-treated microvessels, incubation of microvessels obtained from the cerebral cortex of yearling sheep resulted in significant reductions in occludin expression after $24 \mathrm{~h}$ of exposure to $100 \mathrm{ng} / \mathrm{ml}$ of IL-6 protein, but not after exposure to 1 or $10 \mathrm{ng} / \mathrm{ml}$ (ANOVA: $\mathrm{F}=4.1, \mathrm{n}=5, \mathrm{p}<0.05$, fig. 2a). Likewise, incubation of microvessels from adult sheep resulted in significant reductions in occludin expression after exposure to $100 \mathrm{ng} / \mathrm{ml}$ of IL-6, but not to 1 or $10 \mathrm{ng} / \mathrm{ml}$ (ANOVA: $\mathrm{F}=5.3, \mathrm{n}=5, \mathrm{p}<0.01$, fig. 2b). Incubation of microvessels obtained from cerebral cortices of yearling sheep resulted in an increase in claudin- 5 expression after $24 \mathrm{~h}$ of exposure to $10 \mathrm{ng} / \mathrm{ml}$ of IL- 6 protein $(\mathrm{n}=5, \mathrm{p}<0.05)$ compared with the control condition, and a decrease after exposure to $100 \mathrm{ng} / \mathrm{ml}$ of IL- 6 protein $(\mathrm{n}=5, \mathrm{p}<0.05)$ compared with the $10 \mathrm{ng} / \mathrm{ml}$ treatment condition (ANOVA: $\mathrm{F}=3.4$, $\mathrm{n}=5, \mathrm{p}<0.05$, fig. 3a). In contrast, incubation of microvessels obtained from cerebral cortex of adult sheep resulted in significant reductions in claudin- 5 expression after $24 \mathrm{~h}$ of exposure to $100 \mathrm{ng} / \mathrm{ml}$ of IL- 6 protein $(\mathrm{n}=5$, $\mathrm{p}<0.05)$, but not to 1 or $10 \mathrm{ng} / \mathrm{ml}$ compared to the control condition (ANOVA: $\mathrm{F}=4.9, \mathrm{n}=5, \mathrm{p}<0.01$, fig. $3 \mathrm{~b}$ ).

\section{IL-6 Neutralizing mAbs Attenuate the Effects of IL-6 on the Expression of Claudin-5}

Incubation of microvessels obtained from adult sheep did not result in significant increases in occludin expression after $24 \mathrm{~h}$ of exposure to IL- 6 protein that had been preincubated with the specific mAb to IL- 6 compared 
with IL-6 alone and anti-IL-6 antibody alone (ANOVA: $\mathrm{F}=1.84, \mathrm{n}=5, \mathrm{p}=0.18$, fig. $4 \mathrm{a}$ ). Claudin -5 expression was significantly higher $24 \mathrm{~h}$ after treatment with IL- 6 protein that had been preincubated with the anti-IL- 6 neutralizing antibody compared with microvessels incubated with IL-6 protein alone and with anti-IL- 6 neutralizing antibody alone (ANOVA: $\mathrm{F}=12.3 \mathrm{n}=5, \mathrm{p}<0.01$, fig. $4 \mathrm{~b}$ ). However, after treatment with IL-6 protein that had been preincubated with anti-IL- 6 neutralizing antibody, the claudin-5 expression remained significantly lower than the expression in control PBS-treated microvessels. In addition, exposure of microvessels to anti-IL-6 antibody alone was also associated with lower claudin- 5 expression when compared with the control PBS-treated condition $(\mathrm{p}<0.01)$. Treatment with the non-specific mouse IgG isotype did not alter the effects of IL-6 protein treatment on the expression of tight junction proteins (data not shown). However, it should be pointed out that our findings shown in figure $2 \mathrm{~b}$ demonstrate a significant decrease in occludin expression in microvessels obtained from adult sheep after treatment with $100 \mathrm{ng}$ of IL-6, whereas the same treatment did not result in similar findings in figure $4 \mathrm{~b}$. Although we cannot entirely account for these discrepant findings, the standard error of the mean appears larger in figure $4 \mathrm{~b}$ than in figure $2 \mathrm{~b}$. Another possibility is that the microvessels were obtained from the brains of sheep from a local supplier and, consequently, were microvessels from outbred sheep. Therefore, the brains from different groups of sheep potentially could have responded differently to the same treatment.

\section{IL-6-Mediated Effects Are Not due to Cell Death as Assessed by the Percent of LDH Release}

The percent of LDH release from the microvessels into the supernatant did not differ among the microvessels that had been exposed to control conditions (PBS) or 1, 10 , or $100 \mathrm{ng} / \mathrm{ml}$ of IL-6 in yearling sheep (ANOVA: $\mathrm{F}=$ $0.01, \mathrm{p}=0.99$, fig. $5 \mathrm{a})$ or adult sheep $(\mathrm{F}=0.44, \mathrm{p}=0.72$, fig. 5b). These findings may be interpreted to suggest that exposure of the microvessels to IL-6 did not result in cell disruption or death in the microvessels.

\section{Discussion}

The purpose of the current study was to examine the effects of incubating ovine cerebral cortical microvessels with different concentrations of IL- 6 on key protein constituents of endothelial tight junctions. Incubation of microvessels isolated from yearling and adult sheep brain

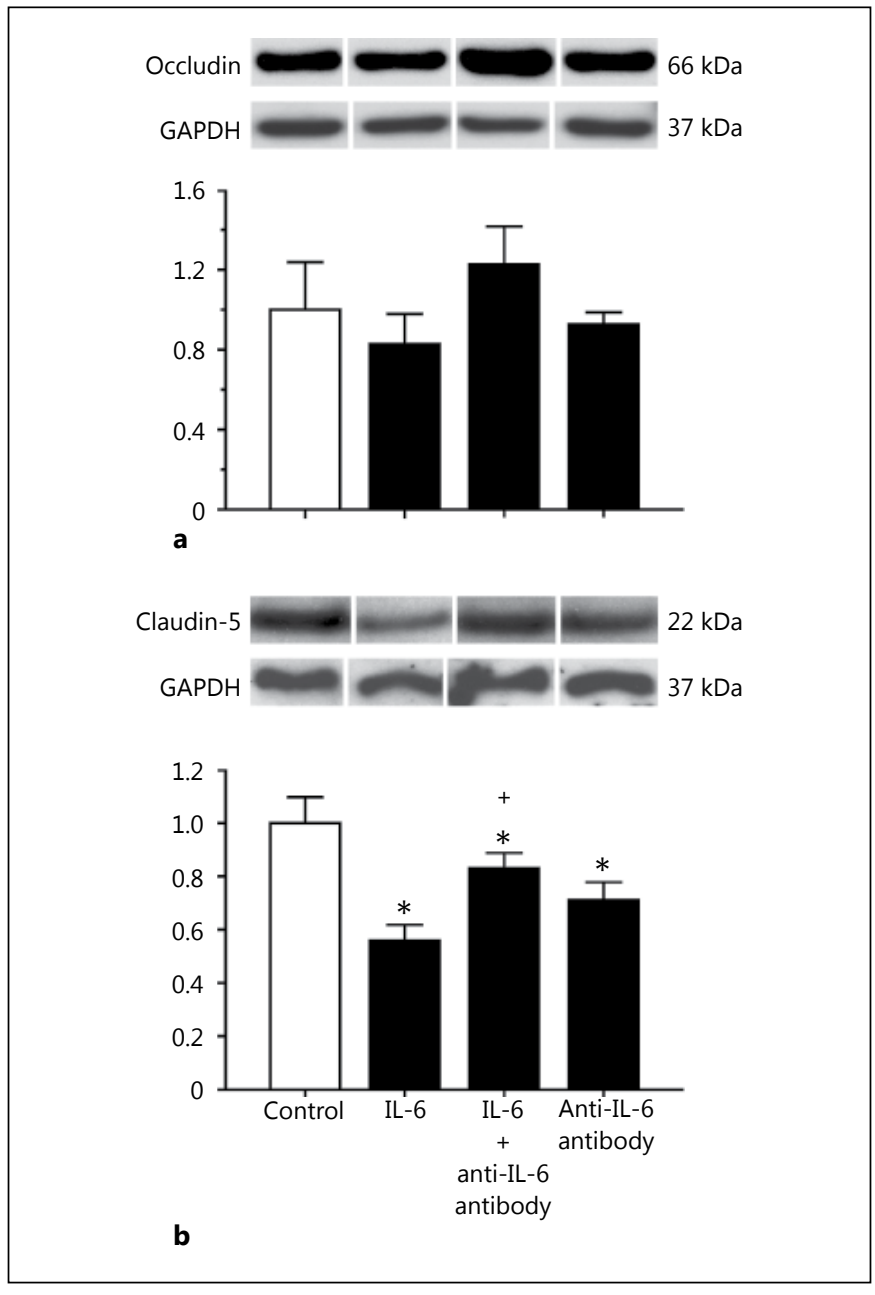

Fig. 4. a Occludin expression in isolated cerebral microvessels from adult sheep after incubation with IL-6 protein $(100 \mathrm{ng} / \mathrm{ml})$, IL-6 protein $(100 \mathrm{ng} / \mathrm{ml})$ preincubated with IL-6 neutralizing mAbs $(1 \mu \mathrm{g} / \mathrm{ml})$, and IL-6 neutralizing mAbs $(1 \mu \mathrm{g} / \mathrm{ml})$ alone. Representative Western immunoblots for occludin and GAPDH. Results are shown as ratios to PBS control treated microvessels. The open bar represents control treated microvessels set to a value of 1 ; closed bars are plotted for IL- 6 alone, IL- 6 plus antiIL- 6 antibody, and anti-IL-6 antibody alone as indicated on the $\mathrm{x}$-axis. $\mathrm{n}=5$ for each group. Values are means \pm SEM. b Claudin-5 expression in isolated cerebral microvessels from adult sheep after incubation with IL- 6 protein, IL- 6 protein preincubated with IL-6 neutralizing mAbs, and IL-6 neutralizing mAbs alone. IL- 6 protein and IL- 6 neutralizing $\mathrm{mAb}$ concentrations are as for a. Representative Western immunoblots for claudin-5 and GAPDH. Results are shown as ratios to PBS control treated microvessels. The open bar represents control treated microvessels set to a value of 1 ; closed bars are plotted for IL- 6 alone, IL- 6 plus anti-IL-6 antibody, and anti-IL- 6 antibody alone as indicated on the $\mathrm{x}$-axis. $\mathrm{n}=5$ for each group. Values are means \pm SEM. ${ }^{*} \mathrm{p}<0.05$ vs. control, ${ }^{+} \mathrm{p}<0.05$ vs. IL- 6 alone and anti-IL-6 antibody alone. 
Fig. 5. a Values represent percent release from microvessels to supernatant in the yearling sheep. Values are plotted for the control, 1, 10, and $100 \mathrm{ng} / \mathrm{ml} \mathrm{IL-6}$ treated microvessels on the $\mathrm{x}$-axis. $\mathrm{n}=5$ for each condition. Values are means \pm SEM. ANOVA: $F=$ $0.01, p=0.99$. IL-6-mediated effects are not due to cell death as assessed by percent LDH release from microvessels. b Values represent percent release from microvessels to supernatant in the adult sheep. Conditions and numbers are as for figure a. ANOVA: $\mathrm{F}=0.01$, $\mathrm{p}=0.99$. IL-6 mediated effects are not due to cell death as assessed by percent LDH release from microvessels.

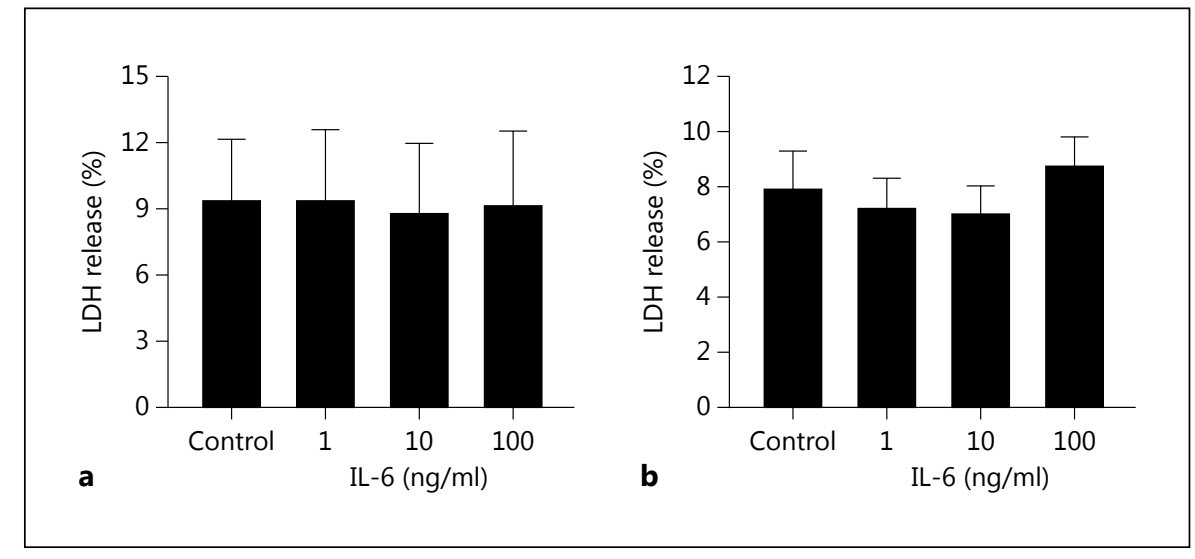

with IL- 6 protein resulted in decreased expression of the tight junction protein occludin, and incubation of microvessels from adult sheep brain resulted in decreased expression of claudin-5. Incubation of microvessels from adult sheep with anti-IL-6 neutralizing antibodies attenuated the effects of IL- 6 on the expression of claudin-5. The finding that IL- 6 reduces the expression of claudin- 5 is important because claudin-5 forms the primary 'seal' of the tight junction and restricts transfer of low molecular weight molecules from the blood to the brain $[2,35]$. Likewise, the finding that IL-6 reduces the expression of occludin is also important as this tight junction protein plays an important role as a support molecule and in modulating tight junction function [1].

Several previous studies support the contention that pro-inflammatory cytokines increase the permeability of endothelial cell confluent monolayers in vitro $[14,16,17]$. IL-6 has been shown to increase the permeability of bovine aortic endothelial cell confluent monolayers measured with albumin via mechanisms that appear to involve morphological changes in cell shape, gap formation between adjacent cells, and rearrangement of F-actin [14]. Similarly, IL-6 was shown to increase the permeability of human umbilical vein endothelial cell confluent monolayers via mechanisms associated with redistribution of the tight junctional protein $\mathrm{ZO}-1$, redistribution of cytoskeletal actin, increased cell contraction, and disorganization of the intercellular borders [17]. In addition, IL-6 appears to contribute to increases in the vascular permeability of the retinal endothelial barrier, whose properties are similar to those of the blood-brain barrier [16]. Consistent with evidence suggesting that IL-6 increases the permeability of nonbarrier endothelial monolayers $[14,17]$ and of the retinal endothelial barrier [16], we have shown that IL-6 decreased occludin and clau- din-5 expression in the endothelium of microvessels, which are known to possess the characteristics of an intact blood-brain barrier [20]. Hence, our findings, combined with the previous results, suggest that IL- 6 increases barrier permeability via changes in cell shape, gap formation between adjacent cells, rearrangement in F-actin, redistribution in the tight junction protein $\mathrm{ZO}-1$, disorganization of intercellular borders [14, 17], and possibly via reductions in the expression of occludin and claudin-5. However, because we did not determine the microvessel permeability in our study, we cannot comment upon the potential contributions of the decreases in tight junction protein expression to increases in permeability that were observed in the former studies $[14,16,17]$.

In the current study, the concentrations of IL-6 to which the cerebral cortical microvessels were exposed were selected based upon levels known to be associated with brain damage in infants [11-13]. We observed decreases in occludin expression in microvessels from the yearling and adult brains after $24 \mathrm{~h}$ of exposure to $100 \mathrm{ng} / \mathrm{ml}$, but not after exposure to the lower concentrations and, similarly, decreases in claudin- 5 expression in microvessels from adult brains after exposure to $100 \mathrm{ng} / \mathrm{ml}$, but not after 1 or $10 \mathrm{ng} / \mathrm{ml}$. These concentration-related decreases in tight junction protein expression are also consistent with previous in vitro work showing increased permeability of bovine aortic and human umbilical vein endothelial cell monolayers after exposure to IL-6 in similar concentrations for comparable durations $[14,17]$. However, although previous studies have also shown that exposure to IL-6 both for shorter [14] and for longer [17] durations was associated with changes in endothelial monolayer permeability, we only examined the effect of microvessel exposure to IL-6 for $24 \mathrm{~h}$. Thus, we cannot comment upon the effects of different durations of IL- 6 
exposure on changes in microvessel tight junction protein expression. However, as an initial step in this study, we selected the 24 -hour exposure to IL- 6 because this cytokine is elevated in the serum of neonates within $24 \mathrm{~h}$ after the development of sepsis, and IL- 6 demonstrated the best sensitivity and specificity to predict sepsis [36]. In addition, sepsis/infection-related inflammation is well known to be associated with significant neurodevelopmental impairment in infants [37].

It is also important to note that exposure of microvessels from the brains of yearling sheep to $10 \mathrm{ng} / \mathrm{ml}$ of IL-6 was actually associated with an increase in claudin-5 expression compared with control treated microvessels (fig. 3). In this regard, IL-6 is known to have both proinflammatory and anti-inflammatory or neuroprotective roles under normal and pathophysiological conditions [38]. Hence, it would appear that exposure of microvessels from yearling, but not adult, sheep to relatively low $(10 \mathrm{ng} / \mathrm{ml})$ concentrations of IL- 6 actually increased the expression of claudin-5, potentially suggesting a neuroprotective role of this pro-inflammatory cytokine on microvessels from the younger animals. These findings suggest that the effects of IL- 6 on the microvasculature also appear to be age related, even though the microvessels from both age groups were derived from relatively mature subjects.

TNF- $\alpha$ has been shown to play a critical role in the development of brain edema, increased blood-brain barrier permeability by disruption of tight junctions, and loss of the tight junction-associated protein occludin in an adult mouse model of acute liver failure [39]. These findings, taken together with the findings in our study, suggest that the pro-inflammatory cytokines IL- 6 and TNF- $\alpha$ both have the ability to alter the characteristics of the bloodbrain barrier by their effects on the protein constituents of endothelial tight junctions. In addition, these findings suggest that occludin and claudin-5 are vulnerable to the effects of these pro-inflammatory cytokines and that the downregulation of these tight junction proteins could affect the structural integrity of tight junctions $[39,40]$.

To confirm that IL- 6 alone downregulated the expression of occludin and claudin-5, we investigated the ability of anti-IL-6 neutralizing antibodies to attenuate the effects of IL- 6 on the expression of the tight junction proteins in the microvessels. Concordant with previous findings [14], incubation of microvessels from adult sheep with anti-IL-6 neutralizing antibodies attenuated the effects of IL- 6 on the expression of claudin-5 (fig. $4 \mathrm{~b}$ ). However, treatment with the neutralizing antibodies did not return claudin-5 expression to levels similar to those ob-

IL-6 and Tight Junction Proteins served in control treated microvessels. In addition, antiIL-6 antibody treatment also decreased claudin- 5 expression. Other potential factors such as IL-6-mediated local increases in vascular endothelial growth factor and protein kinase $\mathrm{C}$ or upregulation of other cytokines could also have contributed to the downregulation of occludin and claudin-5 expression $[17,40]$, thereby limiting the efficacy of treatment with the anti-IL-6 neutralizing antibody. The neutralizing monoclonal (mAb) anti-human IL-6 antibody (Cell Sciences) that we used has specificity for the recombinant IL- 6 that we used and exerts its biological activity by inhibiting IL- 6 binding to its receptor, so that at least some of the IL-6-related downregulation of the tight junction proteins probably resulted from IL-6 receptor-related events.

Claudin-5 expression also decreased after exposure to the anti-IL-6 neutralizing antibody alone. The treatment of the microvessels with anti-IL6 antibody alone could have decreased endogenous levels of IL- 6 within the microvessels. IL- 6 has both pro- and anti-inflammatory properties [38]. Therefore, treatment of the microvessels with anti-IL-6 antibody alone could have affected the endogenous levels of IL- 6 within the microvessels, which could in turn have affected other factors that could account for a lower claudin-5 expression compared to the control condition treated microvessels.

Although the pattern of change in the effects of the anti-IL-6 neutralizing antibodies on the expression of occludin (fig. 4a) was similar to those of claudin-5, we did not detect similar significant attenuations on the effects of IL-6 protein on occludin expression, most likely because of the larger standard errors of the mean in the latter. IL-6 treatment also did not result in a statistically significant decrease in occludin expression (fig. 4a) similar to that observed in the dose-exposure study (fig. 2b). Although we cannot entirely account for the discrepancy in the response of the microvessel to IL- 6 exposure, i.e. the decrease in occludin after incubation with $100 \mathrm{ng} / \mathrm{ml}$ IL-6 in figure 2 and lack of a significant decrease in figure $4 a$, inspection of figure 4 suggests relatively wide standard errors of the mean, potentially accounting for the discrepancy. In addition, the larger standard errors for occludin (fig. 4a) compared with claudin-5 (fig. 4b), after exposure to same treatment conditions, could account for the significant findings for claudin-5, but not occludin. In addition, the microvessels were obtained from the brains of sheep from a local supplier and, consequently, were microvessels from outbred sheep. Therefore, the brains from different groups of sheep potentially could have responded differently to the same treatment.

Neuroimmunomodulation 2013;20:264-273 
The mechanism(s) by which IL-6 downregulates tight junction protein expression cannot be discerned by our study. However, occludin and claudin-5 are connected to cytoplasmic proteins such as zonula occludens 1,2 , and 3 , which in turn are coupled to actin [5]. IL-6 results in an endothelial redistribution of zonula occludens- 1 and actin $[14,17]$ and, consequently, the reductions in occludin and claudin-5 expression along with changes in zonula occludens- 1 and actin could affect the integrity of tight junctions [40]. Moreover, consistent with previous work [14], the reductions in tight junction protein expression were not a result of cytotoxic microvascular cell death because we did not observe increases in the percent of $\mathrm{LDH}$ release from the microvessels into the supernatant in the treated microvessels (fig. 5).

There are several limitations to our study. Although we measured occludin and claudin-5 protein expression in the microvessels, we did not determine immunohistochemical localization of the tight junction proteins. It would be important to determine the effect of IL- 6 on the distribution of tight junction proteins in microvessels in future studies. We do not know whether the effects of the changes in the levels of tight junction proteins are associated with changes in barrier permeability as has been previously reported using other models $[14,17]$. In addition, we recognize that incubation of the microvessels could have been associated with remodeling, cell division, or growth. However, it must be emphasized that the microvessels exposed to the control condition and different amounts of IL-6 exposure were treated in precisely the same fashion and came from the same pool of brain tissue, thus validating our comparisons among the different treatment conditions. In addition, it would have been interesting to have evaluated different intervals of incuba- tion times, which we will consider for future studies. Lastly, we would have preferred to perform these studies in microvessels from brains of immature sheep. However, as an initial step to establish this in vitro blood-brain barrier model in our laboratory, we used cadaveric brains from yearling and adult sheep that were available in sufficient quantities from a local supplier. Studies of the effects of inflammatory agents on the immature brain vasculature are particularly relevant to brain injury in the fetus and newborn [11-13]. Nonetheless, our present findings (fig. 3) suggest that examining the effects of IL-6 in the immature brain could yield interesting results that could differ from those in the adult brain (fig. 3).

Previous work has postulated that during maternal inflammation or infection cytokines originating in the uterus, amniotic fluid, or placenta could enter the fetal circulation and cross and/or damage the fetal/neonatal bloodbrain barrier [41]. Based upon the findings of the current study, we speculate that pro-inflammatory cytokine-mediated brain damage could result, in part, from the downregulation of tight junction proteins at the blood-brain barrier, impairing the integrity of the barrier and thereby rendering the blood-brain barrier more permeable to circulating substances toxic to the brain.

\section{Acknowledgments}

Research reported in this publication was supported by the $\mathrm{Na}$ tional Institute of General Medical Sciences of the National Institutes of Health under award number 1R01-HD-057100. The content is solely the responsibility of the authors and does not necessarily represent the official views of the National Institutes of Health. We also would like to acknowledge the excellent editorial assistance of Courtney A. Hill, PhD.

\section{References}

1 Hawkins BT, Davis TP: The blood-brain barrier/neurovascular unit in health and disease. Pharmacol Rev 2005;57:173-185.

$\checkmark 2$ Abbott NJ, Patabendige AA, Dolman DE, Yusof SR, Begley DJ: Structure and function of the blood-brain barrier. Neurobiol Dis 2010; 37:13-25.

-3 Farquhar MG, Palade GE: Junctional complexes in various epithelia. J Cell Biol 1963;17: 375-412.

4 Abbott NJ, Ronnback L, Hansson E: Astrocyte-endothelial interactions at the bloodbrain barrier. Nat Rev Neurosci 2006;7:41-53.

5 Forster C: Tight junctions and the modulation of barrier function in disease. Histochem Cell Biol 2008;130:55-70.
6 Erickson MA, Dohi K, Banks WA: Neuroinflammation: a common pathway in CNS diseases as mediated at the blood-brain barrier. Neuroimmunomodulation 2012;19:121-130.

7 Leviton A, Gilles F, Neff R, Yaney P: Multivariate analysis of risk of perinatal telencephalic leucoencephalopathy. Am J Epidemiol 1976;104:621-626.

-8 D'Alquen D, Kramer BW, Seidenspinner S, Marx A, Berg D, Groneck P, Speer CP: Activation of umbilical cord endothelial cells and fetal inflammatory response in preterm infants with chorioamnionitis and funisitis. Pediatr Res 2005;57:263-269.

-9 Leviton A, Hecht JL, Allred EN, Yamamoto H, Fichorova RN, Dammann O: Persistence after birth of systemic inflammation associated with umbilical cord inflammation. J Reprod Immunol 2011;90:235-243.

10 Hagberg H, Mallard C, Jacobsson B: Role of cytokines in preterm labour and brain injury. BJOG 2005;112:16-18.

11 Foster-Barber A, Ferriero DM: Neonatal encephalopathy in the term infant: neuroimaging and inflammatory cytokines. Ment Retard Dev Disabil Res Rev 2002;8:20-24.

12 Martin-Ancel A, Garcia-Alix A, Pascual-Salcedo D, Cabanas F, Valcarce M, Quero J: Interleukin-6 in the cerebrospinal fluid after perinatal asphyxia is related to early and late neurological manifestations. Pediatrics 1997; 100:789-794 
13 Shalak LF, Laptook AR, Jafri HS, Ramilo O, Perlman JM: Clinical chorioamnionitis, elevated cytokines, and brain injury in term in fants. Pediatrics 2002;110:673-680.

14 Maruo N, Morita I, Shirao M, Murota S: IL-6 increases endothelial permeability in vitro. Endocrinology 1992;131:710-714.

15 Gurkan OU, He C, Zielinski R, Rabb H, King LS, Dodd OJ, D’Alessio FR, Aggarwal N, Pearse D, Becker PM: Interleukin-6 mediates pulmonary vascular permeability in a two-hit model of ventilator-associated lung injury. Exp Lung Res 2011;37:575-584.

-16 Noma H, Funatsu H, Mimura T: Vascular endothelial growth factor and interleukin- 6 are correlated with serous retinal detachment in central retinal vein occlusion. Curr Eye Res 2011;37:62-67.

-17 Desai TR, Leeper NJ, Hynes KL, Gewertz BL: Interleukin-6 causes endothelial barrier dysfunction via the protein kinase $\mathrm{C}$ pathway. J Surg Res 2002;104:118-123.

18 Sun D, Lytle C, O’Donnell ME: IL-6 secreted by astroglial cells regulates $\mathrm{Na}-\mathrm{K}-\mathrm{Cl}$ cotransport in brain microvessel endothelial cells. Am J Physiol 1997;272:C1829-C1835.

19 Jacob A, Hartz AM, Potin S, Coumoul X, Yousif S, Scherrmann JM, Bauer B, Decleves $\mathrm{X}$ : Aryl hydrocarbon receptor-dependent upregulation of Cyp1b1 by TCDD and diesel exhaust particles in rat brain microvessels. Fluids Barriers CNS 2011;8:23-35.

20 Vernon H, Clark K, Bressler JP: In vitro models to study the blood brain barrier. Methods Mol Biol 2011;758:153-168.

-21 Baldwin SA, Cairns MT, Gardiner RM, Ruggier R: A D-glucose-sensitive cytochalasin $\mathrm{B}$ binding component of cerebral microvessels. J Neurochem 1985;45:650-652.

22 Beart PM, Sheehan KA, Manallack DT: Absence of N-methyl-D-aspartate receptors on ovine cerebral microvessels. J Cereb Blood Flow Metab 1988;8:879-882.
3 Joo F: The cerebral microvessels in culture, an update. J Neurochem 1992;58:1-17.

24 Gunn AJ, Gunn TR, de Haan HH, Williams CE, Gluckman PD: Dramatic neuronal rescue with prolonged selective head cooling after ischemia in fetal lambs. J Clin Invest 1997;99. 248-256.

25 Stonestreet BS, Patlak CS, Pettigrew KD, Reilly CB, Cserr HF: Ontogeny of blood-brain barrier function in ovine fetuses, lambs, and adults. Am J Physiol 1996;271:R1594-R1601.

26 Back SA, Riddle A, Hohimer AR: Role of instrumented fetal sheep preparations in defining the pathogenesis of human periventricular white-matter injury. J Child Neurol 2006; 21:582-589.

27 Bernhard CG, Kolmodin GM, Meyerson BA: On the prenatal development of function and structure in the somesthetic cortex of the sheep. Prog Brain Res 1967;26:60-77.

28 Cook CJ, Gluckman PD, Johnston BM, Williams C: The development of the somatosensory evoked potential in the unanaesthetized fetal sheep. J Dev Physiol 1987;9:441455.

29 Stonestreet BS, Sadowska GB, Leeman J, Hanumara RC, Petersson KH, Patlak CS: Effects of acute hyperosmolality on blood-brain barrier function in ovine fetuses and lambs. Am J Physiol Regul Integr Comp Physiol 2006; 291:R1031-R1039.

30 Sanchez del Pino MM, Hawkins RA, Peterson DR: Neutral amino acid transport by the blood-brain barrier: membrane vesicle studies. J Biol Chem 1992;267:25951-25957.

-31 Sussman I, Carson MP, McCall AL, Schultz V, Ruderman NB, Tornheim K: Energy state of bovine cerebral microvessels: comparison of isolation methods. Microvasc Res 1988;35: 167-178.

32 McCall AL, Valente J, Cordero R, Ruderman NB, Tornheim K: Metabolic characterization of isolated cerebral microvessels: ATP and ADP concentrations. Microvasc Res 1988;35: 325-333.
33 Korzeniewski C, Callewaert DM: An enzymerelease assay for natural cytotoxicity. J Immunol Methods 1983;64:313-320.

\$3 Rauen U, Kerkweg U, Wusteman MC, de Groot H: Cold-induced injury to porcine corneal endothelial cells and its mediation by chelatable iron: implications for corneal preservation. Cornea 2006;25:68-77.

35 Tsukita S, Furuse M: Claudin-based barrier in simple and stratified cellular sheets. Curr Opin Cell Biol 2002;14:531-536.

36 Bender L, Thaarup J, Varming K, Krarup H, Ellermann-Eriksen S, Ebbesen F: Early and late markers for the detection of early-onset neonatal sepsis. Dan Med Bull 2008;55:219223

37 Stoll BJ, Hansen NI, Adams-Chapman I, Fanaroff AA, Hintz SR, Vohr B, Higgins RD: Neurodevelopmental and growth impairment among extremely low-birth-weight infants with neonatal infection. JAMA 2004; 292:2357-2365.

38 Thorns V, Walter GF, Licastro F: Effects of IL6 and IL1beta on aFGF expression and excitotoxicity in NT2N cells. J Neuroimmunol 2002; 127:22-29.

39 Lv S, Song HL, Zhou Y, Li LX, Cui W, Wang W, Liu P: Tumour necrosis factor-alpha affects blood-brain barrier permeability and tight junction-associated occludin in acute liver failure. Liver Int 2010;30:1198-1210.

40 Forster C, Burek M, Romero IA, Weksler B, Couraud PO, Drenckhahn D: Differential effects of hydrocortisone and TNFalpha on tight junction proteins in an in vitro model of the human blood-brain barrier. J Physiol 2008;586:1937-1949.

41 Dammon O, Leviton A: Maternal intrauterine infection, cytokines, and brain damage in the preterm newborn. Pediatric Research 1997; 42:1-8. 